\title{
Bispectral Index Guided Propofol and Remifentanil Anaesthesia: Evaluation of Drug Consumption and Immediate Recovery in a Ghanaian Population
}

\author{
Akwasi Antwi-Kusi ${ }^{1, ~ *}$, Bright Ighodaro Obasuyi ${ }^{2}$ \\ ${ }^{1}$ Department of Anaesthesia and Intensive Care, Komfo Anokye Teaching Hospital, Kumasi, Ghana \\ ${ }^{2}$ Department of Anaesthesiology, University of Port Harcourt Teaching Hospital, Port Harcourt, Nigeria
}

Email address:

antwikusi@yahoo.com (A. Antwi-Kusi)

*Corresponding author

\section{To cite this article:}

Akwasi Antwi-Kusi, Bright Ighodaro Obasuyi. Bispectral Index Guided Propofol and Remifentanil Anaesthesia: Evaluation of Drug Consumption and Immediate Recovery in a Ghanaian Population. Journal of Anesthesiology. Vol. 5, No. 1, 2017, pp. 1-4. doi: $10.11648 /$ j.ja.20170501.11

Received: December 5, 2016; Accepted: January 5, 2017; Published: February 6, 2017

\begin{abstract}
General anaesthesia is a balance between the amount of anaesthetic drug(s) administered and the state of arousal of the patient. Different patients may need variable doses of anaesthetics to reach and maintain a surgical level of anaesthesia. Even though lack of autonomic response suggests sufficient analgesia during surgery, there is no such clear clinical sign for the assessment of the depth and sedation of anaesthesia especially in a paralysed patient. Bispectra index (BIS) monitors the depth of anaesthesia and helps the anaesthetist to deliver the minimal dose of anaesthetic agent required to achieve an adequate hypnotic state. In this study conducted at the Komfo Anokye Teaching Hospital, patients undergoing general anaesthesia received intravenous propofol and remifentanil under BIS monitor as the sole anaeshetic. At the end of the surgery the total amount of propofol and remifentanil consumed and the time it took for the patients to open the eye and respond to verbal commands were noted. Propofol consumption was calculated to beat an averagerate of $5.44 \mathrm{mg} / \mathrm{kg} / \mathrm{h}$ and remifentanil at $13.68 \mathrm{ug} / \mathrm{kg} / \mathrm{h}$ to maintain a surgical level of anaesthesia. The mean time from stopping the anaesthetic agents until the patients opened the eyes and responded to verbal commands were 2.20 minutes and 2.70 minutes respectively. The study found that Propofol and remifentanil infusions at a rate of $5.44 \mathrm{mg} / \mathrm{kg} / \mathrm{h}$ and $13.68 \mathrm{ug} / \mathrm{kg} / \mathrm{h}$ respectively, under BIS monitor, effectively controls intraoperative responses and allow for rapid emergence from anaesthesia in a Ghanaian population.
\end{abstract}

Keywords: Total Intravenous Anaesthesia, Bispectra Index, Remifentanil, Propofol

\section{Introduction}

General anaesthesia is a balance between the amount of anaesthetic $\operatorname{drug}(\mathrm{s})$ administered and the state of arousal of the patient [1]. Different patients may need variable doses of anaesthetics to reach and maintain a surgical level of anaesthesia [2]. It has been established that patients vary widely in their responses to drugs. Genetic factors can account for $20 \%$ to $95 \%$ of patient variability [3]. Genetic polymorphisms for many drug- metabolising enzymes and drug targets [eg. Receptors) have been identified. There are also differences in drug administration, metabolism and excretion among races [2] and these differences are of importance to the anaesthesiologist.
It is therefore necessary to monitor the effect of anesthetic drugs on patients based on individual patient variations. Even though lack of autonomic response suggests sufficient analgesia during surgery, there is no such clear clinical sign available for the assessment of the depth and sedation of anaesthesia especially in a paralysed patient. Standard clinical practice is cautious and anaesthetists may err on the side of safety by administering larger than adequate drug doses in the hope of avoiding awareness [3]. This may lead to the administration of high doses of anaesthetic agents which will delay emergence and affect recovery from anaesthesia.

Bispectra index [BIS) monitor improves anaesthetic delivery by allowing clinicians to administer the minimal dose of agents required to achieve an adequate hypnotic state. 
It is one of several technologies used to monitor the depth of anaesthesia. Titrating the anaesthetic agents to specific bispectra index during general anaesthesia in adults and children over 1 year old allows the anaesthetist to adjust the amount of anesthetic agent to the needs of the patient, possibly resulting in more rapid emergence from anaesthesia.

The non-invasive sensor has self-adhesive backing, much like a typical EEG pad. After wiping the patient's forehead and temple with alcohol and drying the skin to ensure that a quality signal will be obtained, you'll place the sensor across the patient's forehead and over either the left or right temple. The sensor then sends raw EEG information through the cable and converter to the BIS engine. This engine processes the EEG data according to an algorithm that combines select EEG features to produce a BIS index. This index is a number between 0 and 100 that is displayed on the monitor and reflects the patient's level of sedation. A BIS value between 40 and 60 indicates an appropriate level for general anaesthesia as recommended by the manufacturer. The essence of BIS is to process a complex signal (the EEG), analyse it and process the result into a single number $[4,5,6]$

Total intravenous anaesthesia(TIVA) involves the use of intravenous agents for induction and maintenance of anaesthesia. The advantage of TIVA under BIS guidance include rapid emergence from anaesthesia and better recovery characteristics. It has however been reported by Ortolani et al that recovery of Senegalese African Blacks from Intravenous Anesthesia with Propofol and Remifentanil is slower than that of Caucasians. Our experience on recovery characteristics in Ghanaians after TIVA was however different from that reported by Ortolani [7]. Our hypothesis was that West Africans require a lower dose of propofol and remifentanil for total intravenous anaesthesia and that if the normal standard dose is given to Ghanaians and for that matter Africans, it will lead to delayed awakening. There has not been any study on total intravenous anaesthesia using propofol and remifentanil under BIS guidance in Ghana. Our study therefore sought to find the consumption of propofol and remifentanil used for TIVA under BIS guidance among Ghanaians and the characteristics of their recovery.

\section{Methodology}

After institutional ethics approval and patients consent, male and female ASA physical status class I and II who were coming for various elective surgeries under general anaesthesia during the study period were recruited for this research (convenient sampling). The number of patients recruited was restricted to the available research materials like BIS electrodes and the medications available. Exclusion criteria included patients with neurologic disease, patients taking medications that affect the central nervous system, age below 18 or above 70 years, body mass index(BMI) $>35$ and history of previous adverse reaction to any of the drugs to be used for the research. All the patients were fasted over night prior to the surgery. No premedication was given. Patients taking medications like anti-hypertensives that would not affect the anaesthesia were allowed to take their medications on the morning of surgery. An $18 \mathrm{G}$ intravenous canula was inserted into a forearm vein and $500 \mathrm{ml}$ of lactated ringers solution was set up. This was followed by base line monitoring which included oxygen saturation, heart rate, electrocardiogram(ECG), non invasive blood pressure and the bispectral index of the electroencephalogram (BIS A-200 monitor), Aspect Medical System Inc.

Pre-oxgenation was done with oxygen flowing at $5 \mathrm{~L} / \mathrm{min}$ for three (3) minutes. Fentanyl $2 \mu \mathrm{g} / \mathrm{kg}$ was given for preemptive analgesia. Induction of anaesthesia was done with Propofol $2 \mathrm{mg} / \mathrm{kg}$ and titrated till loss of verbal response and eyelash reflex. After the patient was induced to sleep, test ventilation was done and when mask ventilation was satisfactory, the patient was given Rocuronium $0.5 \mathrm{mg} / \mathrm{kg}$ to facilitate tracheal intubation and to maintain neuromuscular block for the surgery. The patient was tracheally intubated and the cuff of the endotracheal tube inflated. The patient was ventilated with oxygen and air with $\mathrm{F}_{\mathrm{i}} \mathrm{O}_{2}$ of $0.4 \%$. Anaesthesia was then maintained with Propofol (Diprivan) $2 \%$ by Astra Zeneca at an initial rate of $6 \mathrm{mg} / \mathrm{kg} / \mathrm{h}$ and Remifentanil(Ultiva) by Glaxo Smithkline at $5 \mu \mathrm{g} / \mathrm{kg}$ body weightthrough the use of a syringe pump.

Mean arterial pressure(MAP), Heart rate (HR) Blood pressure(BP) and bispectra index (BIS) were used to evaluate the depth of anaesthesia. Throughout surgery the propofol infusion was adjusted to maintain a BIS value of between 40 and 60. Remifentanil rate was also adjusted according to the autonomic response: at a pulse rate and non invasive systolic blood pressure greater than $20 \%$ of baseline value respectively, the dose of remifentanil was increased to abolish the autonomic responseAll patientswere also given $1.25 \mathrm{~g}$ novalgin (Novamin sulphate) infused over 5 minutes at 30 minutes before the end of surgery for post operative analgesia.

Approximately fifteen minutes before the end of surgery, the propofol infusion was stopped and the Remifentanil infusion adjusted according to the patient's autonomic response. After the last stitch the remifentanil infusion was also stopped. The skin incision was infiltrated with $20 \mathrm{ml}$ of $0.5 \%$ ropivacaine for post operative analgesia. A nerve stimulator was used to assess neuromuscular function. Patients were extubated when neuromuscular function was adequate and the patient could open the eyes and obey command. No reversal agent was given for neuromuscular block. At the end of the surgery, the total amount of propofol and remifentanil consumed as well as the time taken for the patient to open the eyes spontaneously and respond to verbal command were noted. Any complications noted intra and post operatively were also noted and documented.

\section{Results}

30 patients were enrolled in this study with a mean age of 40.67 and a standard deviation(SD) of 12.01 . There were 18 males and 12 females. The mean weight of the patients was 
65.13 with a SD of 11.64, their mean Body mass Index(BMI) was 23.03 with a SD of 3.41. The type of surgeries done is as presented in Figure 1 below. There were a variety of general surgical and gynaecological cases including thyroidectomies and cholecystectomies. Other surgeries were gynaecological cases like myomectomy and hysterectomy.

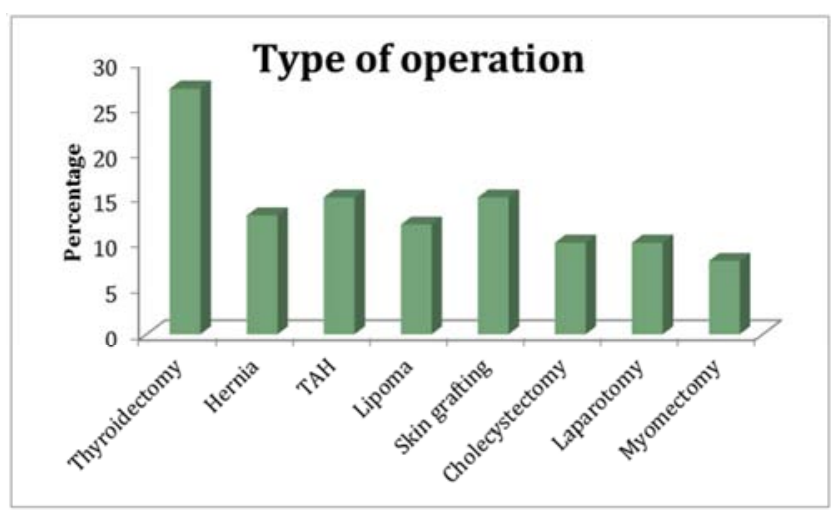

Figure. 1. Type of Operation.

The mean duration of the surgeries was 69.30 minutes with a SD of 19.25 and the mean duration of anaesthesia was 79 . 57 minutes with a SD of 24.38. Table 1 is a summary of the recovery characteristics and amount of drugs consumed. The average amount of propofol consumed was $413.67 \mathrm{mg}$ and that of remifentanil was $1.04 \mathrm{mg}$. The average consumption rate of propofolwas calculated to be $5.44 \mathrm{mg} / \mathrm{kg} / \mathrm{h}$ and that of remifentanilwas calculated to be $13.68 \mathrm{ug} / \mathrm{kg} / \mathrm{h}$. This is lower than the dosage described in standard text books. The time from the end of anaesthesia to eye opening was 2.20 minutes and the time from end of anaesthesia to verbal response was 3.70 minutes. The patients spent an average of 37.7 minutes in the recovery ward.

Table 1. Recovery characteristics of patients and amount of drugs consumed.

\begin{tabular}{llll}
\hline & Mean & S.D & Number \\
\hline End of anaesthesia to eye opening & 2.20 minutes & 0.71 & 30 \\
End of anaesthesia to verbal response & 3.70 minutes & 1.44 & 30 \\
Amount of propofol consumed & $413.67 \mathrm{mg}$ & 120.19 & 30 \\
Amount of remifentanil consumed & $1.04 \mathrm{mg}$ & 0.36 & 30 \\
Infusion rate of propofol & $5.44 \mathrm{mg} / \mathrm{kg} / \mathrm{h}$ & & \\
Infusion rate of remifentanil & $13.68 \mathrm{ug} / \mathrm{kg} / \mathrm{h}$ & & \\
\hline
\end{tabular}

S.D- Standard deviation

The main complication encountered was hypotension which was defined as systolic blood pressure falling below more than $20 \mathrm{mmHg}$. When this happened, the infusion rate of the ringers lactate was increased and the anaesthetic agents reduced. None of the patients reported any experience of intra-operative awareness (table 2).

Table 2. Complications.

\begin{tabular}{ll}
\hline Complications & Incidence \\
\hline Bradycardia & $6.66 \%$ \\
Post operative nausea and vomiting & $6.66 \%$ \\
Hypotension & $13.32 \%$ \\
Awareness & $0.00 \%$ \\
\hline
\end{tabular}

\section{Discussion}

Our results show that intravenous infusions of remifentanil at a rate of $13.68 \mathrm{ug} / \mathrm{kg} / \mathrm{h}$ and propofol $5.44 \mathrm{mg} / \mathrm{kg} / \mathrm{h}$ administered in a TIVA technique under BIS guidance is an effective regimen in Ghanaians, allowing for rapid recovery following anaesthesia. The dose of propofol administered in this study was smaller than the dose typically given for the maintenance of TIVA using propofol. Differences in sensitivity to anaesthetic agents among different races of people have been established $[8,9,10]$. There are also differences in sensitivity towards other medications. These differences may be due to both genetic factors and life style. These lifestyles include nutrition, health, physical exercise etc. For example, Critchley et al found that West Africans show reduced metabolic activation of paracetamol [11]. Iron et al also demonstrated an increased sensitivity to alcohol in a Niger population possibly because of polymorphism of human alcohol dehydrogenase [12]. Due to these differences in sensitivity to drugs among races it is imperative to tailor your anaesthetic drugs to the needs of your patient. In reality this does not happen. Anaesthesia providers will always determine drug dosages as recommended by the manufacturer and standard textbooks. This is partly due to the unavailability of BIS monitor in developing countries to monitor the depth of anaesthesia. Because of this, there is always the fear of under dosing the patient with its attendant risk of awareness under anaesthesia. In order to avoid this problem anaesthesia providers tend to give standard doses of medications to their patients. This may lead to an overdose in certain group of patients due to genetic variations. In the case of total intravenous anaesthesia, this could lead to delayed awakening. A typical example is the research conducted by Ortolani et al, where a group of Black Senegalese Africans and Caucasians were given the same dosages of propofol and remifentanil in a total intravenous anaesthesia technique [7]. At the end of the surgery,they reported delayed awakening in the Black Senegalese patients even though the two groups received the same amount of medications. This delay is attributed to genetic polymorphism. The use of BIS monitor allows you to give the dose that is enough to put your patient to sleep, avoid awareness and also avoid overdose based on the individual patient $[13,14]$.

Our research did not show any differences in the awakening characteristics between males and females. There is abundant information in the literatureon the concept of 'personalized medicine' in which a knowledge of genetic factors- guided prescribing, tailored to the individual, is popularly considered to be an inevitable consequence of completion of the International Human Genome Project [15, 16]. For example Lindi et al has established that race contribute to variability in dosing requirements for warfarin in anticoagulation with African Americans requiring higher doses and Asians requiring lower doses than whites. This difference was attributed to Whites having more of the variant enzyme CYP2C9 than in African Americans [15]. 


\section{Conclusion}

Propofol and remifentanil infusions at a rate $5.44 \mathrm{mg} / \mathrm{kg} / \mathrm{h}$ and $13.68 \mathrm{ug} / \mathrm{kg} / \mathrm{h}$ respectively under BIS monitor effectively controls intraoperative responses and allow for rapid emergence from anaesthesia in a Ghanaian population.

\section{Limitations}

The main limitation of this study is that it is a fairly small study based on patients recruited from one hospital. To enhance reliability of the results, the study size would need to be much higher.

\section{Acknowledgement}

The authors would like to thank Professor Michael Georgieff for generously donating the BIS monitor and its electrodes and all the drugs used for this research. We would also like to thank Mr Brookman, the chief executive officer ofHospital Engineering Limited for transporting the research materials from Germany to Ghana.

\section{References}

[1] Kalow W, Tang BK, Endrenyi L. Hypothesis: comparisons of inter- and intra-individual variations can substitute for twin studies in drug research. Pharmacogenetics 1998; 8:283-289.

[2] U. S. Food and Drug Administration, U.S. Dept. of Health and Human Services. International Conference on Harmonisation: guidance on ethnic factors in the acceptability of foreign clinical data availability. Federal Register 1998; 63:31790 31796.

[3] H. L Kaul and Neerja Bharti, Monitoring depth of anaesthesia. Indian J Anaesth 2010; 46: 323-332.

[4] Rosow C, Manberg PJ, Bispectra index monitoring. Anesthesiol Clin North America2001; 19: 947-966.

[5] Gan TJ, Glass PS, Windsor A, et al. Bispectra index monitoring allows faster emergence and improved recovery from propofol, alfentanil and nitrous oxide. Anesthesiology 1997; 87: 808-815.
[6] Rampil I J. A primer for EEG signals processing in anaesthesia. Anesthesiology 1998; 89: 980-1002.

[7] Ortolani O, Conti A, Sall B. et al The recovery of Senegalese African Blacks from Intravenous Anaesthesia with Propofol and Remifentanil is slower than that of Caucasians. Anesth Analg 2001;93:1222-1226.

[8] Houghton IT, ChanK, Wong YC, et al. Pethidine pharmacokinetics after intramuscular dose: a comparison in Caucasian, Chinese and Nepalese patients. Clin Pharmacol 1992; 14: 451-458.

[9] Chan A, Nickoll E, Thorton C, et al. Spontaneous movement after injection of propofol. Anesthesia 1996; 51: 663-666.

[10] Short TG, Aun CST, Tan H. Prospective evaluation of pharmacokinetic model-controlled infusion of propofol in paediatric patients. Br J Anaesthesia 1994; 72: 302-330.

[11] Critchley JA, Nimmo GR, Gregson CA, et al. Intersubject and ethnic differences in paracetamol metabolism. Br $\mathrm{J}$ Clin Pharmacol 1986; 22: 649-657.

[12] Iron A, Groppi A, Fleury B, et al. Polymorphism of class I alcohol dehydrogenase in French, Vietnamese and Niger populations: genotyping by PCR amplification and RFLP analysis of dried blood spot. Ann Genet 1992; 35: 152-156.

[13] Shepherd J, Jones J, et al Clinical effectiveness and costeffectiveness of depth of anaesthesia monitoring (E-Entropy, Bispectra index and Narcotrend): a systematic review and economic evaluation. Health Technol Assess 2013; 34: 1-264.

[14] Gan TJ, Glass PJ, Windsor et al Bispectra Index monitoring allows faster emergence and improved recovery from propofol, alfentanil and nitrous oxide anaesthesia. Anesthesiology 1997; 87: 808-815.

[15] Lindi NA, Arnett DK, Acton RT. Influence of CYP2C9 and VKORC11173C/T genotype on the risk of haemorrhagic complication in African-American and European-American patients on warfarin. Clin pharmacol. Ther. 2008; 83: 312321 .

[16] Cordell HJ, Clayton DG. Genetic association studies Lancet 2005; 366: 1121-31. 